Special Issue of the 7th International Advances in Applied Physics and Materials Science (APMAS 2017)

\title{
A Numerical Study of the Effect of Wave Amplitude on the Efficiency of a Wave Power System
}

\author{
G. OZDAMAR ${ }^{a, *}, \mathrm{Y}$. PEKBEY ${ }^{b}$ AND A. OZDAMAR ${ }^{b}$ \\ ${ }^{a}$ Ege University, Graduate School of Natural and Applied Sciences, Department of Mechanical Engineering, \\ 35100 Izmir, Turkey \\ ${ }^{b}$ Ege University, Faculty of Engineering, Department of Mechanical Engineering, 35100 Izmir, Turkey \\ An oscillating water column wave energy system consists of a barrier (front wall), a wave turbine, an electric \\ generator and an air chamber (air column). The parts of a system must be improved to increase efficiency of \\ the system in general. The dimensions of the air chamber affect directly the efficiency of the system because the \\ conversion of the wave power into the air movement is realized here, thus the wave parameters are important. One \\ of the characteristic parameters for waves is their amplitude. In this study, the system is simulated in $2 \mathrm{D}$ and \\ solved numerically to see the effect of water wave amplitude on the efficiency of energy system. In the design of \\ this system the barrier length is constant. The numerical modelling involves computational fluid dynamics analysis \\ and optimization of the oscillating water column. The Navier-Stokes equations and the continuity equation are \\ numerically solved based on the finite volume method using the commercial ANSYS Fluent code. In the numerical \\ model the flow is assumed to be inviscid, unsteady, and incompressible. The efficiency of oscillating water column \\ system is first increased up to $67 \%$ and then decreases to $50 \%$ with the increase of the wave amplitude.
}

DOI: 10.12693/APhysPolA.134.153

PACS/topics: environmental physics, efficiency of the oscillating water column, optimization, finite volume method, wave energy

\section{Introduction}

As a renewable energy source, wave energy has many advantages, such as having the highest energy density among the renewable energy sources and minimal negative effect on environment [1-3]. Due to these advantages, wave energy is being used more in the recent years. Wave energy can be converted into electricity by wave energy converters which are generally known as wave turbines.

Wave turbines are classified in three main groups: wave energy systems that are using shape-shifting movement of the body or body movement, systems using the water pressure and systems using the air pressure for producing electrical energy. The oscillating water column (OWC) wave energy converter is the third type system, which uses the air pressure. It is the most extensively studied type of converters [4-13]. The schematic representation of the system is shown in Fig. 1.

The efficiency of an OWC wave energy converter depends on the barrier (front wall), the wave turbine, the electric generator, the air chamber (air column), and wave parameters (wave length and wave amplitude). In this study, the effect of the wave amplitude on the OWC wave turbine efficiency is investigated and optimum wave amplitude is determined. For this aim, water waves are modeled using the CFD software, ANSYS Fluent. It is assumed that the length of the generated wave is $1 \mathrm{~m}$ and

*corresponding author; e-mail: gokhan.ozdamar@ege.edu.tr value of the height of the wave is varied between $0.002 \mathrm{~m}$ and $0.008 \mathrm{~m}$. The wave tank has length of $10 \mathrm{~m}$ and height of $6 \mathrm{~m}$.

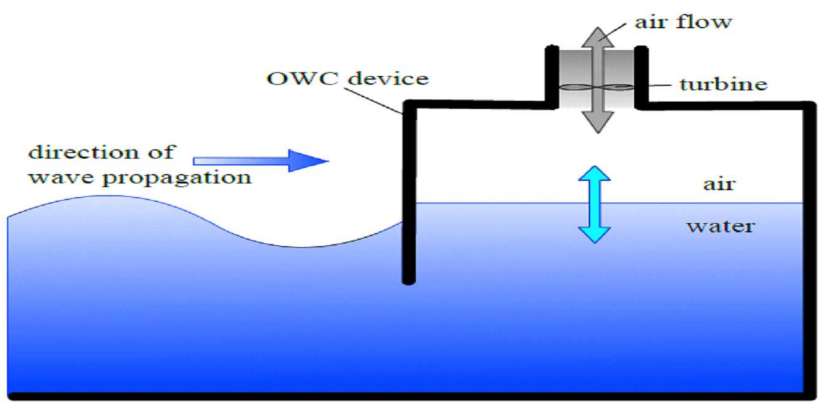

Fig. 1. Schematic diagram of oscillating water column.

\section{Problem definition and theoretical solution}

In this study, a two-dimensional boundary value problem is considered to find the efficiency of the wave turbine using ANSYS Fluent. ANSYS Fluent is a commercial software which solves the continuity and momentum (Navier-Stokes) equations based on the finite volume method.

$$
\begin{aligned}
& \nabla V=0, \\
& \frac{\partial V}{\partial t}=-\nabla(V V)-\nabla p+\nu \nabla^{2} V+g .
\end{aligned}
$$

Here $V, p, \nu, g$ are velocity, pressure, kinematic viscosity of the water and the gravity respectively [15]. Efficiency of a wave energy converter can be calculated by the following equation: 


$$
\eta=\frac{P_{\text {flow }}}{P_{\text {wave }}},
$$

where $P_{\text {flow }}$ and $P_{\text {wave }}$ are power of water flow and wave power, respectively [16]. $P_{\text {flow }}$ and $P_{\text {wave }}$ are given in the Eq. (4) and Eq. (5), respectively.

$$
\begin{aligned}
& P_{\text {flow }}=\frac{1}{2} \rho_{\mathrm{a}} A V^{3}, \\
& P_{\text {wave }}=\frac{1}{16} \rho_{\mathrm{w}} g H^{2} C\left[1+\frac{2 k d}{\sinh (2 k d)}\right],
\end{aligned}
$$

where $d$ is water depth, $H$ is wave height, $\rho_{\mathrm{a}}$ is air density $\left(1.23 \mathrm{~kg} / \mathrm{m}^{3}\right), \rho_{\mathrm{w}}$ is water density $\left(1000 \mathrm{~kg} / \mathrm{m}^{3}\right), g$ is the gravitational acceleration $\left(9.81 \mathrm{~m} / \mathrm{s}^{2}\right), A$ is the cross section area of the chamber along streamwise direction, $C$ is horizontal wave velocity and $V$ is the vertical air velocity in air chamber.

The numerical modelling involves CFD analysis of the OWC optimization. The Navier-Stokes equations were solved numerically based on the finite volume method using commercial code, ANSYS Fluent. In the numerical model the flow was assumed to be inviscid, unsteady and incompressible. Water waves, with the wave length of $1 \mathrm{~m}$, were modeled in a numerical wave tank, where ANSYS Fluent dynamic mesh feature and the volume of fluid (VOF) model were used.

Figure 2 shows a schematic diagram of investigated wave energy converter. The wave amplitude was assigned with the values $\xi_{\mathrm{a}}=0.002 \mathrm{~m}, 0.004 \mathrm{~m}, 0.006 \mathrm{~m}$, and $0.008 \mathrm{~m}$ to find the best wave amplitude for this converter system.

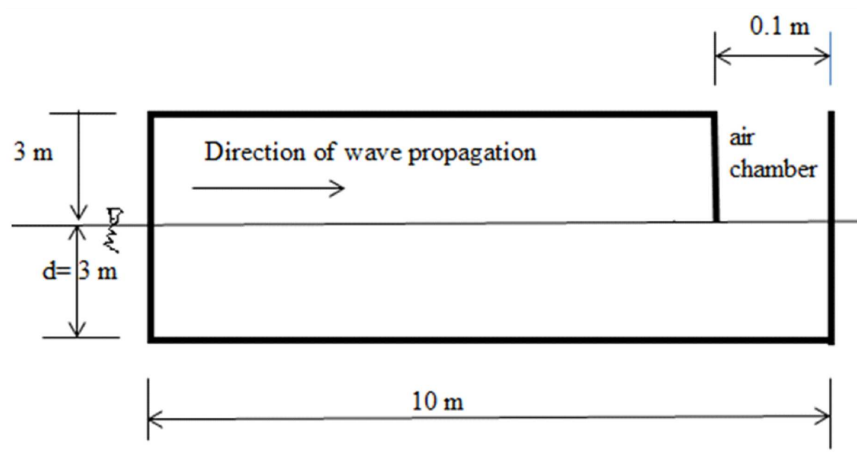

Fig. 2. Schematic diagram of investigated wave energy converter.

To simulate numerically the wave in a wave tank, a piston-type wave maker was used and controlled waves with the desired amplitude and frequency were created by hooking a user defined function.

Generated wave with desired amplitude and frequency is given in Fig. 3. As seen in Fig. 3, the wave amplitude is $0.006 \mathrm{~m}$ and wave period is $0.8 \mathrm{~s}$. A wave that has a period of $0.8 \mathrm{~s}$ should pass the point, located $4 \mathrm{~m}$ from the left, in $3.2 \mathrm{~s}$. As understood from Fig. 3, wave has occurred after $4.8 \mathrm{~s}$ and approximately after about $10 \mathrm{~s}$ it reaches the desired form.

The average velocities in the air chamber during the wave period and the efficiencies for each wave amplitude are numerically calculated and are given in Table I.

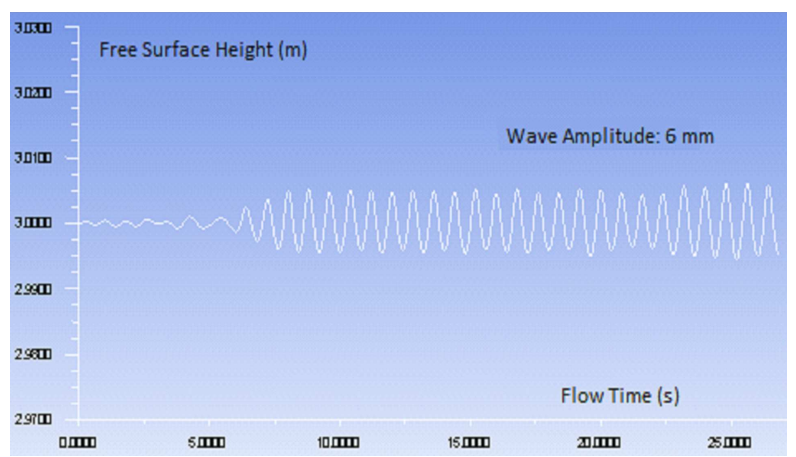

Fig. 3. Free water surface height vs. flow time at $4 \mathrm{~m}$ distance.

TABLE I

OWC system efficiency as function of wave amplitude

\begin{tabular}{c|c|c|c}
\hline \hline $\begin{array}{c}\text { Case } \\
\text { number }\end{array}$ & $\begin{array}{c}\text { Wave } \\
\text { amplitude }[\mathrm{m}]\end{array}$ & $\begin{array}{c}\text { Average velocity } \\
\text { in air chamber }[\mathrm{m} / \mathrm{s}]\end{array}$ & $\begin{array}{c}\text { OWC system } \\
\text { efficiency [\%] }\end{array}$ \\
\hline 1 & 0.002 & 0.40 & 32 \\
\hline 2 & 0.004 & 0.74 & 52 \\
\hline 3 & 0.006 & 1.07 & 67 \\
\hline 4 & 0.008 & 1.16 & 50
\end{tabular}

\section{Results and conclusions}

As seen in the Table I and Fig. 4, the efficiency of OWC system is first increases up to $67 \%$ and then decreases to $50 \%$ with the increasing wave amplitude. The maximum efficiency for the given system occurs at wave amplitude of $0.006 \mathrm{~m}$, with the maximum value of $67 \%$. The investigated wave turbine can be used in conditions with wave amplitude of $2 \mathrm{~mm}$ (min. efficiency) or $6 \mathrm{~mm}$ (max. efficiency). It is obvious that the turbine can produce more energy if it runs in wave conditions with $6 \mathrm{~mm}$ amplitude. Over 25 years of life, if the turbine works under these conditions, the achieved energy gain will be very high. As a conclusion, it is found that selecting the wave turbine parameters according to the wave amplitude is very important.

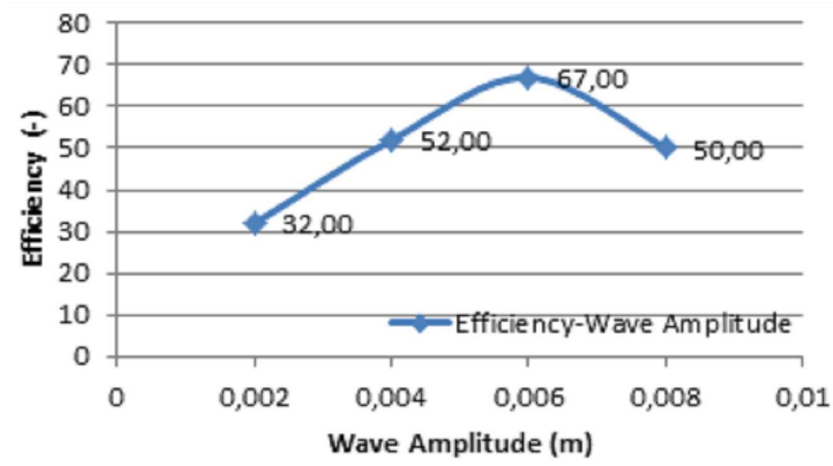

Fig. 4. Efficiency (\%) vs. wave amplitude. 


\section{References}

[1] B. Drew, A. Plummer, M.N. Sahinkaya, J. Pow. Ener. 223, 887 (2009).

[2] T.W. Thorpe, A Brief Review of Wave Energy. Technical Report No.120, Energy Technology Supprt Unit (ETSU), Report Produced for the UK Department of Trade and Industry 1999.

[3] A. Clement, P. McCullen, A. Falcao, A. Fiorentino, F. Gardner, K. Hammarlund, G. Lemonis, T. Lewis, K. Nielsen, S. Petroncini, M.T. Pontes, P. Schild, B.O. Sjöström, H.C. Sorensen, T. Thorpe, Renew. Sust. Energy Rev. 6, 405 (2002).

[4] U. Şentürk, A. Özdamar, Math. Comput. Appl. 16, 630 (2011).

[5] M.E. McCormick, J. Hydron. 8, 77 (1974).

[6] A. Hiramoto, Int. Symp. Wave Tide Ener. 73, 83 (1978).
[7] D.V. Evans, J. Ins. Math. App. 17, 155 (1995).

[8] A.J.N.A. Sarmento, A.F. de O. Falcao, J. Fluid Mech. 150, 467 (1985).

[9] D.V. Evans, J. Fluid Mech. 114, 481 (1982).

[10] T. Kim, M. Takao, T. Setoguchi, K. Kaneko, M. Inoue, Int. J. Therm. Sci. 40, 681 (2001).

[10] T. Setoguchi, S. Santhakumar, M. Takao, T.H. Kim, K. Kaneko, Renew. Ener. 28, 79 (2003).

[12] A. F. De O. Falcão, R.J.A. Rodrigues, Appl. Ocean Res. 24, 59, (2002).

[13] G. Özdamar, M. Mut, Y. Pekbey, A. Özdamar, Dicle Uni. Müh. Fak. Müh. Der. (2016), 7-3-569-576 MD16-050, (in Turkish).

[14] C. Peuker, Bachelor Thesis, Institute of Numeric Simulation, University of Bonn 2011. 